\title{
Evaluation of Vibration Characteristics and Theoretical Analysis for In-Wheel Driving Electric Road Vehicle
}

\author{
Shawki Abouel-seoud, Mohamed N. Mansy, Mahmoud Elshaabany, Manar Eltantawie, Eid Ouda
}

\begin{abstract}
Hub-motor driven electric vehicles consider the upcoming technology in the vehicle industry. It has several merits such as lightweight, good accelerator responsiveness, flexibility when designing different drivetrains, operated at most operative efficiency points, and increased space-saving compared with the traditional electric vehicle driven by a central motor. The energy demand around the world is increasing dramatically. So, the researchers seek to find alternatives to the non-renewable resources represented by fossil fuels. Electric vehicles are the most suitable vehicle to avail of this type of energy due to their high efficiency and zero fuel consumption and emission. The electric-powered vehicle is distinctive with low noise and vibration which improves the vibration characteristics compared with internal combustion engine vehicles. In this paper, eight degrees of freedom passive quarter car suspension system of an in-wheel drive powered electric vehicle equipped with a battery/ultracapacitor hybrid energy storage system is studied and analyzed. The system was simulated and tested in both time and frequency domains via the MATLAB/Simulink environment.

Keywords: Electric Vehicles, Quarter Car, In-wheel Motors, Vibration Characteristics, battery/ultracapacitor.
\end{abstract}

\section{INTRODUCTION}

$\mathrm{B}_{\text {is }}$ efforts are employed to solve the problem of diminishing non-renewable resources and save the world from harmful emissions emitted from the internal combustion engine vehicles. Electric vehicle (EV) is one of the most promising technologies in the last decade. It offers a great solution for the oil shortage and global warming problem [1]. The vehicle vibration responses are determined by its suspension system performance to isolate the vehicle from the vibration produced from the road and powertrain. The in-wheel motor electric vehicle is an electric vehicle in which the motor is installed on the hub of each wheel. The main

Revised Manuscript Received on October 25, 2020.

* Correspondence Author

Mahmoud Elshaabany*, Automotive and Tractors Engineering Department, Faculty of Engineering, Mattaria, Helwan University, Cairo, Egypt. Email: Eng_Mah_Hamed@hotmail.com

Shawki Abouel-seoud, Automotive and Tractors Engineering Department, Faculty of Engineering, Mattaria, Helwan University, Cairo, Egypt.Email: s_a_seoud@hotmail.com

Mohamed N. Mansy, Automotive and Tractors Engineering Department, Faculty of Engineering, Mattaria, Helwan University, Cairo, Egypt. Email: Email: eng.noshy@hotmail.com

Manar Eltantawie, Mechanical Engineering Department, Higher Technological Institute, Giza, Egypt Email: manartantawie@gmail.com

Eid Ouda, Automotive and Tractors Engineering Department, Faculty of Engineering, Mattaria, Helwan University, Cairo, Email: eng.eid80@gmail.com

(c) The Authors. Published by Blue Eyes Intelligence Engineering and Sciences Publication (BEIESP). This is an open access article under the CC BY-NC-ND license (http://creativecommons.org/licenses/by-nc-nd/4.0/) merit of this design is decreasing the mechanical losses of the powertrain. However, the existence of the motors in each wheel hub increases the weight of the un-sprung mass which consequently increases the vehicle vibration [2]. A vibration isolation analysis for both light-duty and heavy-duty vehicle suspension systems had been analyzed to study their vibration characteristics. A passive half-car model of five degrees of freedom had designed to examine their dynamic response under the sinusoidal input of rough road via the MATLAB/Simulink environment [3]. A quarter car model for vehicle vibration response consists of eleven degrees of freedom had demonstrated using Scilab-Xcos software. The objective of this work was to enhance the ride quality of passengers by optimizing passenger cushion seat structure. The simulation results confirmed that the seat cushion had a great role in the enhancement of passenger comfort. The vertical displacement and acceleration of the passenger's head are decreased when the seat cushion is used compared with the model without a seat cushion. Passenger comfort is enhanced by optimizing the parameters of the seat cushion [4]. The ride and handling performance for an electric vehicle convert from an internal combustion engine vehicle had estimated. A mathematical model of 14 degrees of freedom for ride and handling had been built. A hydraulic actuated active suspension system is implemented to suit the EV conversion's ride and handling performance. The results showed that the enhancement was done by the active suspension system for the converted vehicle in both ride comfort and handling performance which can be considered as an alternative to the real electric vehicle suspension system [5]. A method for optimizing the vehicle suspension system is designed to improve the vehicle road holding, ride comfort, workspace, and prevent vehicle rollover. The vehicle suspension system considered eleven degrees of freedom and the most significant factor of this work is to prevent the rollover and the suspension functions are also considered. The vertical acceleration of the passenger seat is produced from a random road profile which is estimated by the power spectral density of the road in the frequency domain and is an assessment for the vehicle vibration quality. The fishhook maneuver is done by using a mathematical model for roll motion and the dynamic performance of the variables is considered according to the rollover threshold. The objective of the optimization technique, in this case, is minimizing the vertical acceleration and roll angle considering the physical limitation and safety of the model. The model results emphasized that the optimization technique decreases the vertical motion and keeps it at the desired boundary

Published By:

Blue Eyes Intelligence Engineering and Sciences Publication 


\section{Evaluation of Vibration Characteristics and Theoretical Analysis for In-Wheel Driving Electric Road Vehicle}

values in the frequency domain according to ISO 2631 and also increases the rollover resistance which improves the vehicle ride comfort [6].The passenger ride comfort had improved in an electric vehicle via a new speed control strategy.

This strategy is based on generating a longitudinal speed pattern against longitudinal acceleration/deceleration which presents the source of passenger's discomfort. The control algorithm was based on the optimal control algorithm and the generated speed pattern is evaluated according to vehicle longitudinal jerk which is the derivative of vehicle longitudinal acceleration. The control algorithm's effectiveness was studied via numerical experiments and compared with some conventional techniques. The results showed that the proposed control strategy can improve the passenger ride comfort compared with the conventional methods [7].

This paper aims to investigate the vibration quality of an electric-powered vehicle equipped with a battery/ultracapacitor hybrid energy storage system. In this paper, A quarter electric vehicle suspension system is proposed using MATLAB/Simulink environment. The passenger organs acceleration was estimated to measure the passenger comfort. The acceleration is estimated in both time and frequency domains. This work is organized into seven sections. A brief introduction is presented in the first section. The second section demonstrates the passive suspension system of the electric-powered quarter EV which is propelled with an in-wheel motor. The vertical exciting force generated from the random road profile and the in-wheel motor is evaluated in the third section. The fourth section discussed the random road profile which is used to test the proposed quarter EV vibration response. The estimation of vibration characteristics of the proposed quarter $\mathrm{EV}$ had been elucidated in the fifth section. The sixth section demonstrated and analyzed the simulation results of the proposed EV model in both the time history and frequency domain. Finally, the work conclusion is expressed.

\section{VEHICLE SUSPENSION SYSTEM}

For the simulation work, A passive suspension system for eight DOF quarter in-wheel motor electric-powered EV model with seat and passenger is proposed to study the passenger ride comfort. The quarter car model in [8] had been improved to analysis the in-wheel quarter EV ride quality. In this case, the passenger organs can be modeled as passenger organs masses which are joined together with various springs and dampers elements. The quarter car model includes the unsprung mass which contains the in-wheel motor mass, the vehicle sprung mass, frame mass, and seat\& cushion mass. There are different springs and dampers between each two mass to connect them. The passenger body can be described by several masses for his organs which include thigh and pelvis, lower torso, upper torso, and head. These masses are joined as aforementioned by springs and dampers. This model is used to study the vibration response of the proposed quarter EV model and passenger body organs in both the time and frequency domains. The model also is constructed to simulate the vehicle and human body to improve the EV vibration quality without performing the real experimental work which can expose the vehicle passenger to a risk that threatens his life. The whole system is shown in Fig 1. The parameters of the proposed quarter car model and passenger are described and summarized in Table I.
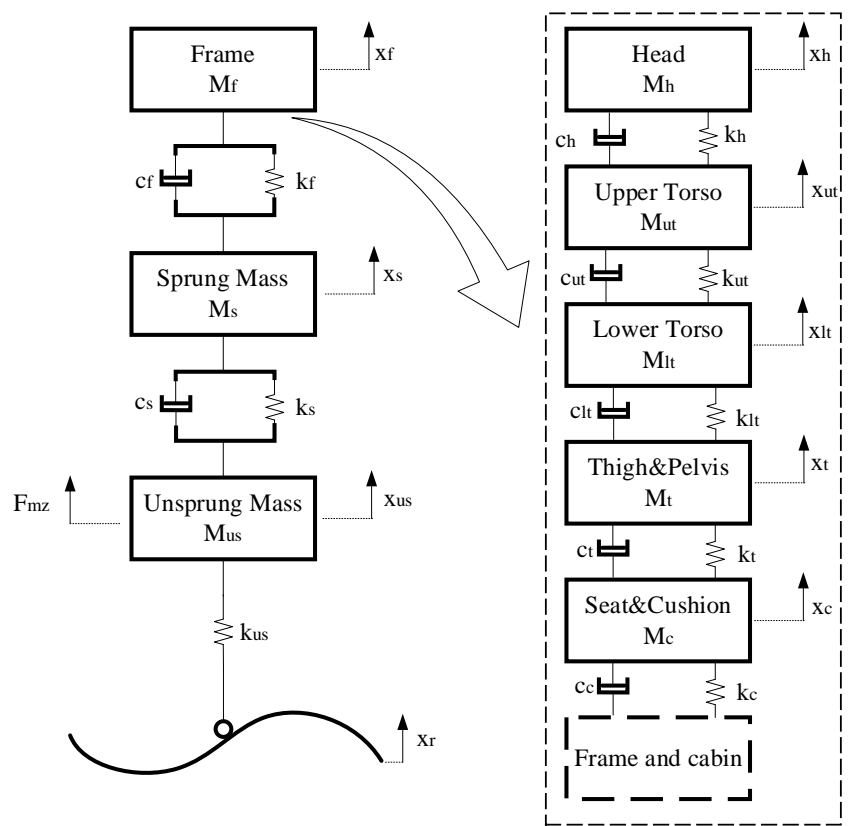

Fig. 1 Modified QCM with passenger interaction [8]

The in-wheel motor vertical exciting force $\left(\mathrm{F}_{\mathrm{mz}}\right)$ is generated due to using the electric motor in the wheel hub. So, its effect reveals in the unsprung mass. The governing equations which describe the quarter car and passenger can be expressed as:

$$
\begin{aligned}
& \mathrm{m}_{\mathrm{us}} \mathrm{x}_{\mathrm{us}}{ }^{\prime \prime}=-\mathrm{k}_{\mathrm{us}}\left(\mathrm{x}_{\mathrm{us}}-\mathrm{x}_{\mathrm{r}}\right)+\mathrm{k}_{\mathrm{s}}\left(\mathrm{x}_{\mathrm{s}}-\mathrm{x}_{\mathrm{us}}\right)+\mathrm{c}_{\mathrm{s}}\left(\mathrm{x}_{\mathrm{s}}-\mathrm{x}_{\mathrm{us}}\right)+\mathrm{F}_{\mathrm{mz}} \\
& \mathrm{m}_{\mathrm{s}} \mathrm{x}_{\mathrm{s}}{ }^{*}=-\mathrm{k}_{\mathrm{s}}\left(\mathrm{x}_{\mathrm{s}}-\mathrm{x}_{\mathrm{us}}\right)-\mathrm{c}_{\mathrm{s}}\left(\mathrm{x}_{\mathrm{s}}-\mathrm{x}_{\mathrm{us}}\right)+\mathrm{k}_{\mathrm{f}}\left(\mathrm{x}_{\mathrm{f}}-\mathrm{x}_{\mathrm{s}}\right)+\mathrm{c}_{\mathrm{f}}\left(\mathrm{x}_{\mathrm{f}}-\mathrm{x}_{\mathrm{s}}\right) \\
& \mathrm{m}_{\mathrm{f}} \mathrm{x}_{\mathrm{f}}=-\mathrm{k}_{\mathrm{f}}\left(\mathrm{x}_{\mathrm{f}}-\mathrm{x}_{\mathrm{s}}\right)-\mathrm{c}_{\mathrm{f}}\left(\mathrm{x}_{\mathrm{f}}-\mathrm{x}_{\mathrm{s}}\right)+\mathrm{k}_{\mathrm{c}}\left(\mathrm{x}_{\mathrm{c}}-\mathrm{x}_{\mathrm{f}}\right)+\mathrm{c}_{\mathrm{c}}\left(\mathrm{x}_{\mathrm{c}}-\mathrm{x}_{\mathrm{f}}\right) \\
& \mathrm{m}_{\mathrm{c}} \mathrm{x}_{\mathrm{c}}{ }^{\prime \prime}=-\mathrm{k}_{\mathrm{c}}\left(\mathrm{x}_{\mathrm{c}}-\mathrm{x}_{\mathrm{f}}\right)-\mathrm{c}_{\mathrm{c}}\left(\mathrm{x}_{\mathrm{c}}-\mathrm{x}_{\mathrm{f}}\right)+\mathrm{k}_{\mathrm{t}}\left(\mathrm{x}_{\mathrm{t}}-\mathrm{x}_{\mathrm{c}}\right)+\mathrm{c}_{\mathrm{t}}\left(\mathrm{x}_{\mathrm{t}}-\mathrm{x}_{\mathrm{c}}\right) \\
& \mathrm{m}_{\mathrm{t}} \mathrm{x}_{\mathrm{t}}{ }^{\prime \prime}=-\mathrm{k}_{\mathrm{t}}\left(\mathrm{x}_{\mathrm{t}}-\mathrm{x}_{\mathrm{c}}\right)-\mathrm{c}_{\mathrm{t}}\left(\mathrm{x}_{\mathrm{t}}-\mathrm{x}_{\mathrm{c}}\right)+\mathrm{k}_{\mathrm{lt}}\left(\mathrm{x}_{\mathrm{lt}}-\mathrm{x}_{\mathrm{t}}\right)+\mathrm{c}_{\mathrm{lt}}\left(\mathrm{x}_{\mathrm{it}}-\mathrm{x}_{\mathrm{t}}\right) \\
& \mathrm{m}_{\mathrm{lt}} \mathrm{x}_{\mathrm{lt}}{ }^{*}=-\mathrm{k}_{\mathrm{lt}}\left(\mathrm{x}_{\mathrm{lt}}-\mathrm{x}_{\mathrm{t}}\right)-\mathrm{c}_{\mathrm{lt}}\left(\mathrm{x}_{\mathrm{lt}}-\mathrm{x}_{\mathrm{t}}\right)+\mathrm{k}_{\mathrm{ut}}\left(\mathrm{x}_{\mathrm{ut}}-\mathrm{x}_{\mathrm{h}}\right) \\
& +\mathrm{c}_{\mathrm{c}}\left(\mathrm{x}_{\mathrm{ut}}-\mathrm{x}_{\mathrm{h}}\right) \\
& \mathrm{m}_{\mathrm{ut}} \mathrm{x}_{\mathrm{ut}}{ }^{\prime}=-\mathrm{k}_{\mathrm{ut}}\left(\mathrm{x}_{\mathrm{ut}}-\mathrm{x}_{\mathrm{lt}}\right)-\mathrm{c}_{\mathrm{ut}}\left(\mathrm{x}_{\mathrm{ut}}-\mathrm{x}_{\mathrm{it}}\right)+\mathrm{k}_{\mathrm{lt}}\left(\mathrm{x}_{\mathrm{lt}}-\mathrm{x}_{\mathrm{t}}\right) \\
& +c_{\mathrm{lt}}\left(\mathrm{x}_{\mathrm{it}}-\mathrm{x}_{\mathrm{t}}\right) \\
& \mathrm{m}_{\mathrm{h}} \mathrm{x}_{\mathrm{h}}{ }^{\prime}=-\mathrm{k}_{\mathrm{h}}\left(\mathrm{x}_{\mathrm{h}}-\mathrm{x}_{\mathrm{ut}}\right)-\mathrm{c}_{\mathrm{h}}\left(\mathrm{x}_{\mathrm{h}}-\mathrm{x}_{\mathrm{ut}}\right)
\end{aligned}
$$

\begin{tabular}{|c|c|c|c|}
\hline Parameter & Description & Value & Unit \\
\hline $\mathrm{m}_{\mathrm{us}}$ & $\begin{array}{l}\text { Unsprung Mass includes } \\
\text { in-wheel motor mass }\end{array}$ & 63 & $\mathrm{~kg}$ \\
\hline $\mathrm{m}_{\mathrm{s}}$ & Sprung Mass & 300 & $\mathrm{~kg}$ \\
\hline $\mathrm{m}_{\mathrm{f}}$ & Frame Mass & 15 & $\mathrm{~kg}$ \\
\hline $\mathrm{m}_{\mathrm{c}}$ & Cushion and Seat Mass & 1 & $\mathrm{~kg}$ \\
\hline $\mathrm{m}_{\mathrm{t}}$ & Thigh and Pelvis Mass & 12.78 & $\mathrm{~kg}$ \\
\hline$m_{l t}$ & Lower Torso Mass & 8.62 & $\mathrm{~kg}$ \\
\hline $\mathrm{m}_{\mathrm{ut}}$ & Upper Torso Mass & 28.49 & $\mathrm{~kg}$ \\
\hline $\mathrm{m}_{\mathrm{h}}$ & Head Mass & 5.31 & $\mathrm{~kg}$ \\
\hline $\mathrm{k}_{\mathrm{us}}$ & Unsprung mass stiffness & 180 & $\mathrm{kN} / \mathrm{m}$ \\
\hline $\mathrm{k}_{\mathrm{s}}$ & Sprung mass stiffness & 10 & $\mathrm{kN} / \mathrm{m}$ \\
\hline $\mathrm{k}_{\mathrm{f}}$ & Frame stiffness & 31 & $\mathrm{kN} / \mathrm{m}$ \\
\hline $\mathrm{k}_{\mathrm{c}}$ & $\begin{array}{l}\text { Cushion and seat } \\
\text { stiffness }\end{array}$ & 18 & $\mathrm{kN} / \mathrm{m}$ \\
\hline $\mathrm{k}_{\mathrm{ut}}$ & Upper torso stiffness & 183 & $\mathrm{kN} / \mathrm{m}$ \\
\hline $\mathrm{k}_{\mathrm{t}}$ & Thigh and Pelvis stiffness & 90 & $\mathrm{kN} / \mathrm{m}$ \\
\hline $\mathrm{k}_{\mathrm{lt}}$ & Lower torso stiffness & 162.8 & $\mathrm{kN} / \mathrm{m}$ \\
\hline
\end{tabular}

Table I. proposed quarter car model parameters, [8] 


\begin{tabular}{|c|l|c|c|}
\hline $\mathrm{k}_{\mathrm{h}}$ & Head stiffness & 310 & $\mathrm{kN} / \mathrm{m}$ \\
\hline $\mathrm{C}_{\mathrm{s}}$ & $\begin{array}{l}\text { Sprung damping } \\
\text { coefficient }\end{array}$ & 2000 & $\mathrm{~N} . \mathrm{s} / \mathrm{m}$ \\
\hline $\mathrm{C}_{\mathrm{f}}$ & $\begin{array}{l}\text { Frame damping } \\
\text { coefficient }\end{array}$ & 830 & $\mathrm{~N} . \mathrm{s} / \mathrm{m}$ \\
\hline $\mathrm{C}_{\mathrm{c}}$ & $\begin{array}{l}\text { Cushion and seat } \\
\text { damping coefficient }\end{array}$ & 200 & $\mathrm{~N} . \mathrm{s} / \mathrm{m}$ \\
\hline $\mathrm{c}_{\mathrm{ut}}$ & $\begin{array}{l}\text { The upper torso damping } \\
\text { coefficient }\end{array}$ & 4750 & $\mathrm{~N} . \mathrm{s} / \mathrm{m}$ \\
\hline $\mathrm{C}_{\mathrm{t}}$ & $\begin{array}{l}\text { Thigh and pelvis } \\
\text { damping coefficient }\end{array}$ & 2064 & $\mathrm{~N} . \mathrm{s} / \mathrm{m}$ \\
\hline $\mathrm{C}_{\mathrm{lt}}$ & $\begin{array}{l}\text { The lower torso damping } \\
\text { coefficient }\end{array}$ & 4585 & $\mathrm{~N} . \mathrm{s} / \mathrm{m}$ \\
\hline $\mathrm{C}_{\mathrm{h}}$ & head damping coefficient & 400 & $\mathrm{~N} . \mathrm{s} / \mathrm{m}$ \\
\hline
\end{tabular}

\section{IN-WHEEL MOTOR VERTICAL EXCITING FORCE ESTIMATION}

The in-wheel motor vertical exciting force can be evaluated based on the wheel model shown in Fig. 2. As shown, the solid black arrow represents the in-wheel motor torque which propels the quarter $\mathrm{EV}$ whereas the black dashed arrow represents the quarter EV resistances torque which opposite the vehicle direction. The solid red arrow represents the motor traction force whereas the blue arrow represents the opposite vehicle resistance. In this case, the in-wheel motor vertical exciting force $\left(\mathrm{F}_{\mathrm{mz}}\right)$ can be estimated as:

$\mathrm{F}_{\mathrm{mz}}=\left(\frac{\mathrm{T}_{\mathrm{m}}}{\mathrm{R}_{\mathrm{r}}}-\mathrm{F}_{\mathrm{r}}\right) / \varphi$

Where $R_{r}$ is the wheel radius and $\varphi$ is the adhesion coefficient between the tire and road. The $18 \mathrm{~kW}$ in-wheel motors are selected as suitable traction motor for the quarter in-wheel powered EV.

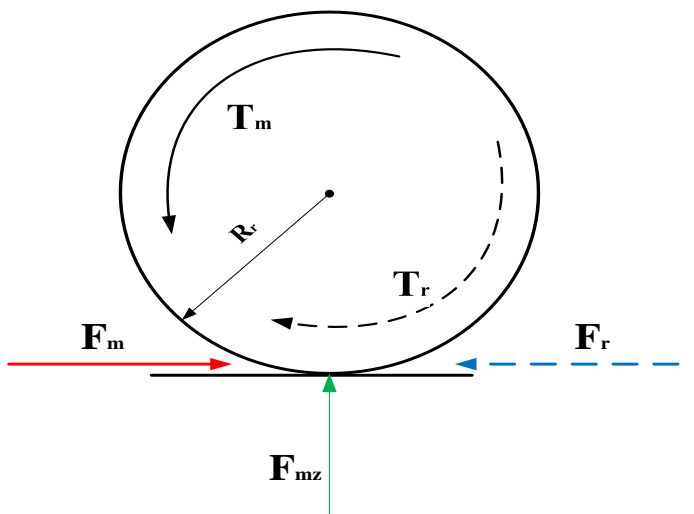

Fig.2 In-wheel motor model

\section{ROAD PROFILE AND DRIVING CYCLE}

The road profile is the excitation to the ride comfort model. The random road profile represents the road roughness during vehicle travel which generates vibration due to the road irregularities. It can be classified based on the ISO 8608 standard. The ISO norm calculates the roughness profile based on the power spectrum density (PSD). The road profile can be classified according to this norm from $\mathrm{A}$ to $\mathrm{H}$. The vertical displacement of the road excitation based on PSD varies with the vehicle travel distance which is from 0 to $\mathrm{L}$ and $L$ is the length of the road profile. The road vertical displacement can be calculated as:

$$
\begin{aligned}
& \mathrm{h}(\mathrm{x})=\sum_{\mathrm{i}=0}^{\mathrm{N}} \sqrt{\Delta \mathrm{n}} 2^{\mathrm{k}} 10^{-3}\left(\frac{\mathrm{n}_{\mathrm{o}}}{\mathrm{i} \Delta \mathrm{n}}\right) \cos \left(2 \pi \mathrm{i} \Delta \mathrm{nx}+\varphi_{\mathrm{i}}\right) \\
& \begin{array}{ll}
\Delta \mathrm{n}=1 / \mathrm{L} \\
\mathrm{N}=\mathrm{L} / \mathrm{V} * 100 \\
\mathrm{~B}=\mathrm{L} / \mathrm{N}
\end{array}
\end{aligned}
$$

Where $\mathrm{x}$ is the abscissa variable in which its points are uniformly divided, $\mathrm{B}$ is the sampling interval between every two points in the abscissa variable( $\mathrm{x}), \mathrm{n}_{\mathrm{o}}$ is the reference value of spatial frequency, $\Delta \mathrm{n}$ is the spatial frequency band, $\mathrm{i}$ is varied from 0 to $\mathrm{N}, \mathrm{N}$ is the number of data points, $\varphi_{\mathrm{i}}$ is random phase angle following a uniform probabilistic distribution within the 0 to $2 \pi$ range and $\mathrm{k}$ is a constant value which determined based on ISO road profile, [9]. It is assumed that the in-wheel powered $\mathrm{EV}$ moves on the ISO road surface class $C$ with a velocity equal to $60 \mathrm{~km} / \mathrm{h}$. The equation parameters are listed in Table II whereas the road elevation versus time is shown in Fig. 3.

Table II. proposed quarter car model parameters, [9]

\begin{tabular}{|c|c|c||c|c|c|}
\hline Parameter & Value & Units & Parameter & Value & Units \\
\hline $\mathrm{n}_{\mathrm{o}}$ & 0.1 & cycle $/ \mathrm{m}$ & $\mathrm{N}$ & 1500 & points \\
\hline $\mathrm{L}$ & 250 & $\mathrm{~m}$ & $\mathrm{k}$ & 4 & - \\
\hline
\end{tabular}

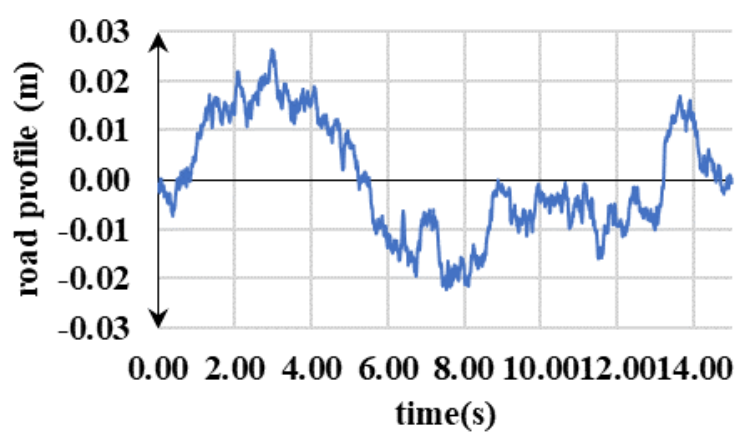

Fig.3 Random road profile versus time

\section{DESIGN VARIABLES}

Equations of motion of (1) to (8) describe the equation of motion of the quarter electric vehicle with vehicle passenger. The in-wheel motor quarter EV has been simulated and solved via the MATLAB/Simulink environment to identify the ride quality of the proposed EV. The EV had driven on the Urban Dynamometer Driving Schedule (UDDS) standard driving cycle. The electric vehicle speed is considered to be equal to $60 \mathrm{~km} / \mathrm{h}$. The in-wheel electric motor vertical exciting force had been estimated over the drive cycle. This force is then implemented in the quarter EV model to show its effect on EV passenger comfort. As previously discussed, the purpose of this work is to investigate the effect of the in-wheel motor vertical force on vehicle ride comfort. The ride comfort performance is examined on a random road profile with a maximum amplitude of $0.028 \mathrm{~m}$ and the test period is 15 seconds. The performance is examined in both the time history and frequency domain.

Published By:

Blue Eyes Intelligence Engineering and Sciences Publication 


\section{Evaluation of Vibration Characteristics and Theoretical Analysis for In-Wheel Driving Electric Road Vehicle}

\section{SIMULATION RESULTS AND DISCUSSION}

\section{A. Time-domain acceleration results}

Fig. 4 shows the time history response of the quarter EV and driver under the random road profile. The ordinary differential equation (ode4) Runge-Kutta solver was used for all the calculations in the MATLAB/Simulink simulation software. Based on the equations of motion from (1) to (8), the system dynamics can be calculated. As presented in Fig.4a, the in-wheel motor and tire assembly (unsprung mass) have a maximum positive acceleration at $1.43 \mathrm{~s}$ while the maximum negative acceleration is reached at $6.43 \mathrm{~s}$. Due to the direct contact of the tire with the road, the maximum acceleration is achieved. The sprung mass acceleration is presented in Fig. 4b. The acceleration of the sprung mass is significantly reduced due to the high damping coefficient. The acceleration of the frame is slightly reduced compared to the sprung mass as indicated in Fig. 4c. The seat cushion is the indication for the passenger ride comfort as it is directly in contact with the passenger. As shown in Fig. 4d, the acceleration is reduced also compared to the frame which increased the passenger ride quality. The passenger organs which contain the pelvis, torso, and head have approximate acceleration values but slightly less than the cushion acceleration as shown in figures $4 \mathrm{~g}, 4 \mathrm{e}, 4 \mathrm{~h}$, and $4 \mathrm{f}$. This indicates that the seat cushion has the most significant effect on passenger comfort.

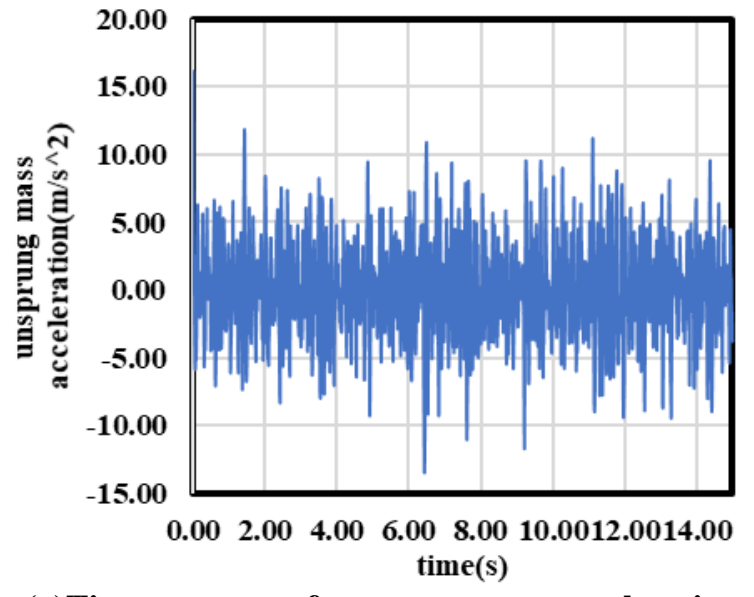

(a)Time response of unsprung mass acceleration



(b)Time response of sprung mass acceleration

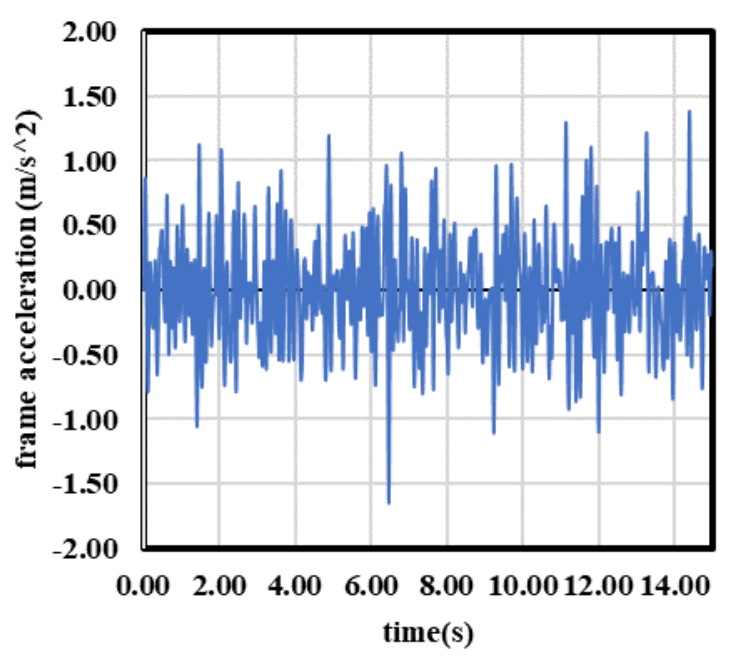

(c)Time response of frame acceleration

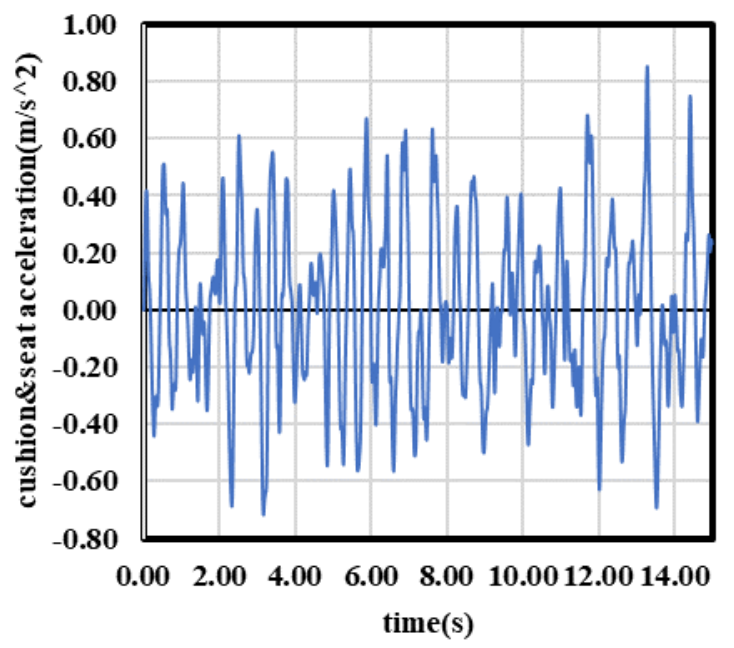

(d)Time response of cushion \& seat acceleration

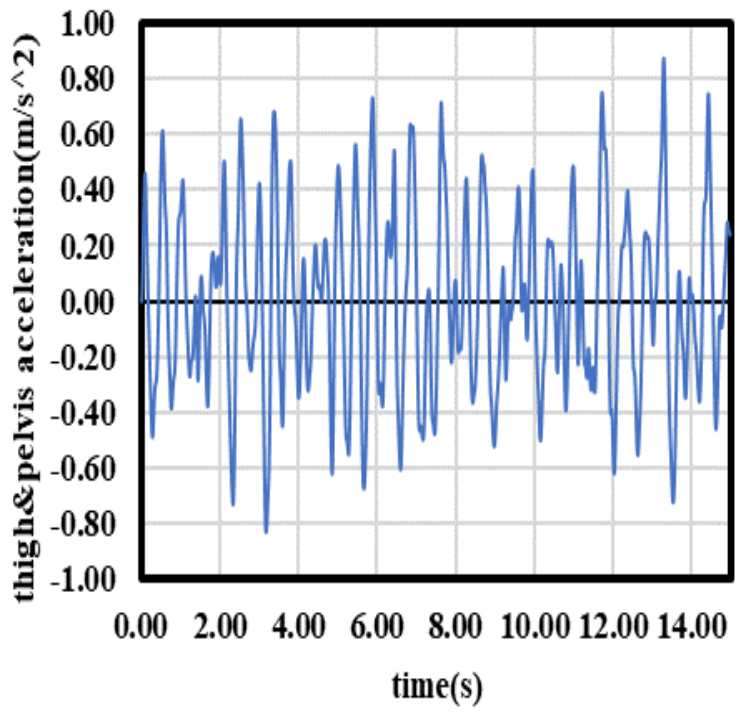

(e)Time response of thigh \& pelvis acceleration

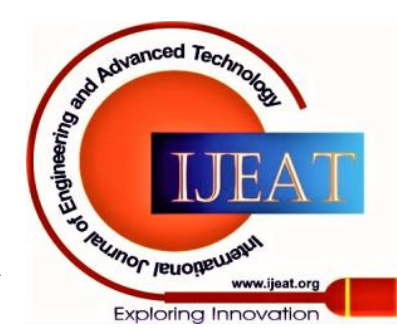




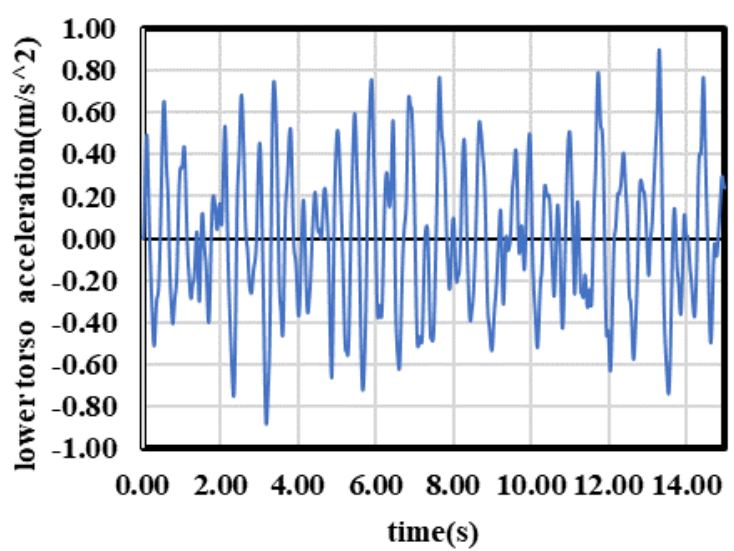

(f)Time response of lower torso acceleration

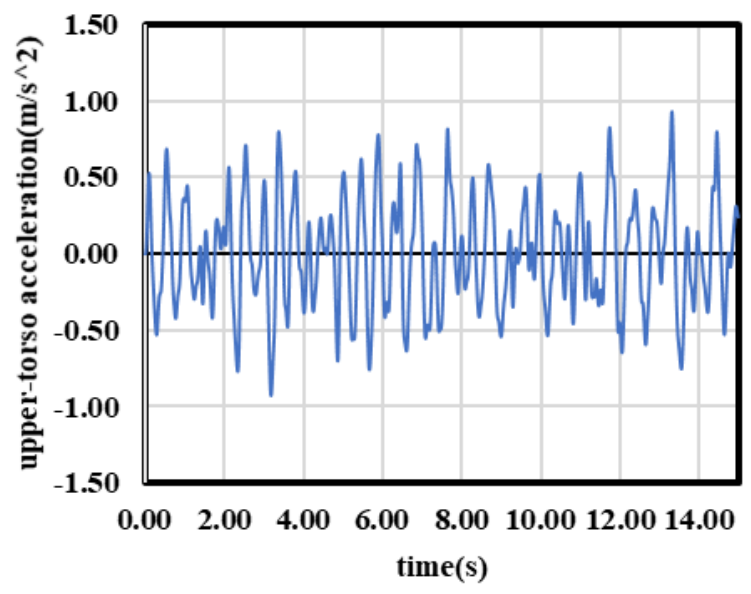

g)Time response of upper torso acceleration

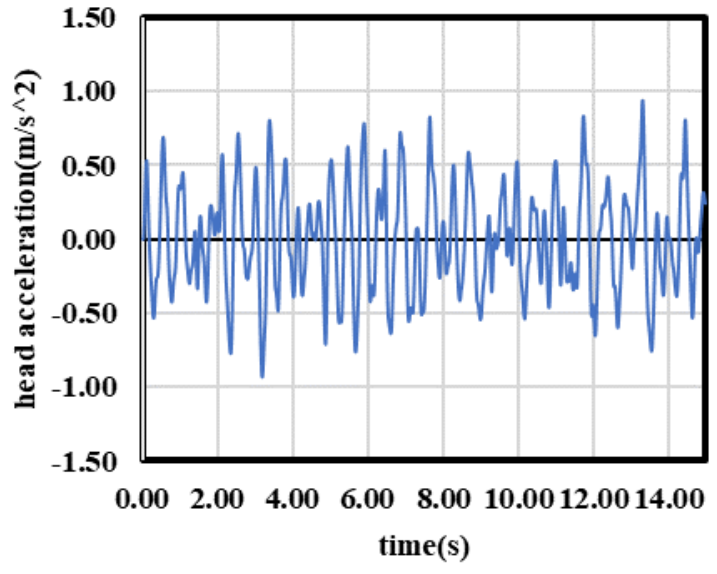

(h)Time response of head acceleration

Fig. 4 The time-domain response of the in-wheel motor quarter EV model

\section{B. Frequency-domain acceleration results}

The EV quarter vehicle frequency response is shown in Fig.5. The frequency response is the relationship between the EV suspension system accelerations and the system frequency. Looking at the plots in Fig. 5a, the unsprung mass has the maximum acceleration at approximately $8.3 \mathrm{~Hz}$. Compared to the rest plots in Fig.5, the unsprung mass has the highest acceleration value as it is in direct contact with the road. The acceleration value of the maximum value of the sprung mass acceleration is significantly reduced compared with the unsprung mass at $8.43 \mathrm{~Hz}$ as presented in Fig. 5b. This occurred due to the high damping coefficient of the shock absorber between the sprung mass and unsprung mass. The maximum acceleration of the frame is slightly decreased compared with the sprung mass at approximately the same previous frequency as shown in Fig. 5c. The maximum acceleration of the seat cushion is slightly increased compared with the frame at low frequency as shown in Fig 4d which has poor ride quality in these frequencies and good ride quality in the rest of the frequencies. The passenger body accelerations as shown in figures $4 \mathrm{~g}, 4 \mathrm{e}, 4 \mathrm{~h}$, and $4 \mathrm{f}$ have high acceleration values compared with the seat cushion at low frequencies (between $1.4 \mathrm{~Hz}$ to $3 \mathrm{~Hz}$ ) which indicates poor ride quality in this bad in these frequencies.

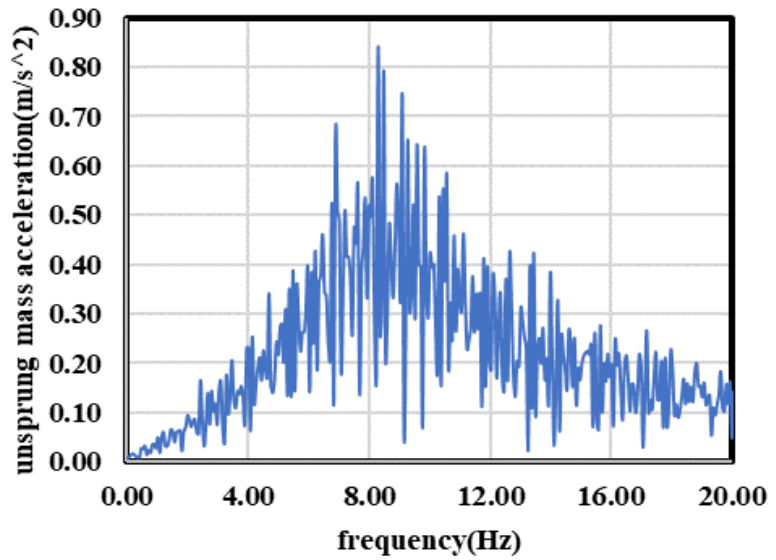

(a)Frequency response of unsprung mass acceleration

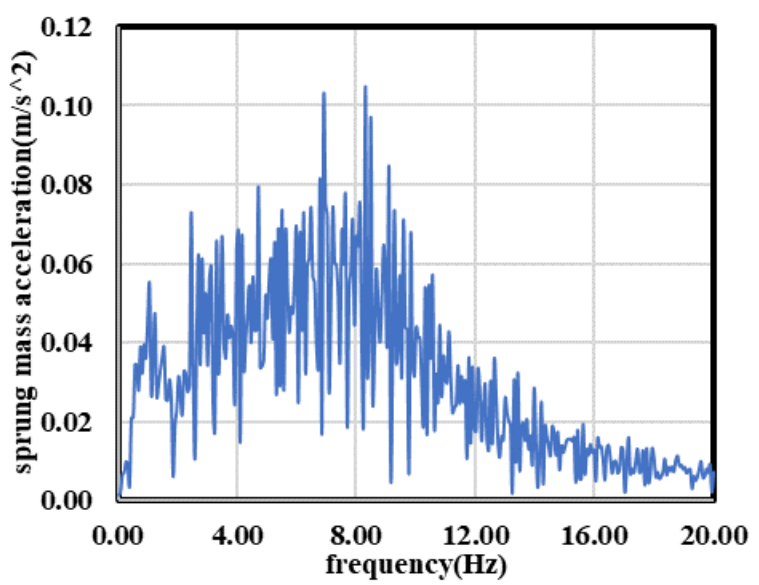

(b)Frequency response of sprung mass acceleration

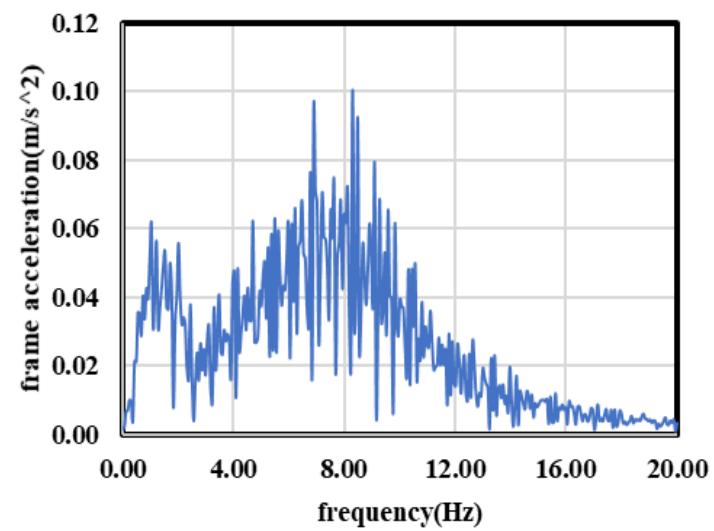

(c)Frequency response of frame acceleration

Published By:

Blue Eyes Intelligence Engineering and Sciences Publication

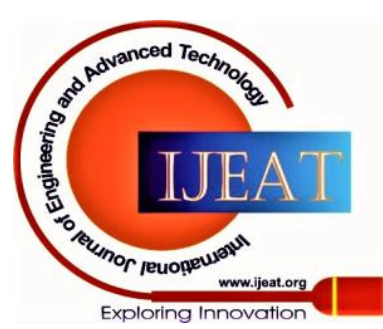




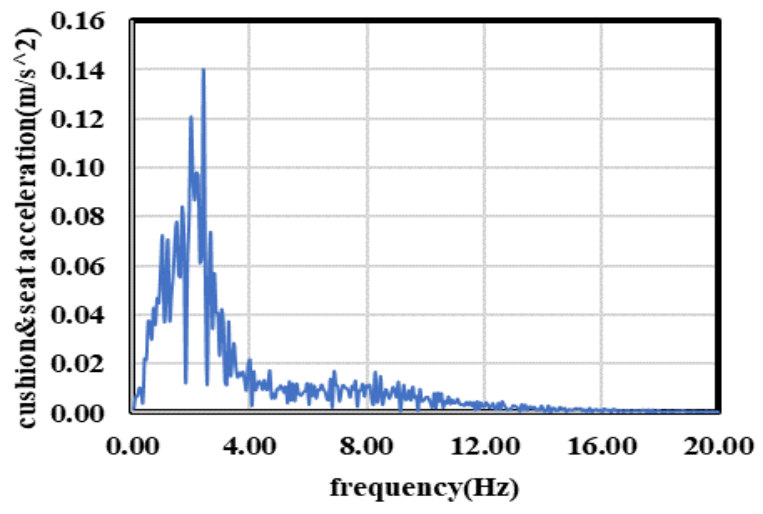

(d)Frequency response of cushion\& seat acceleration

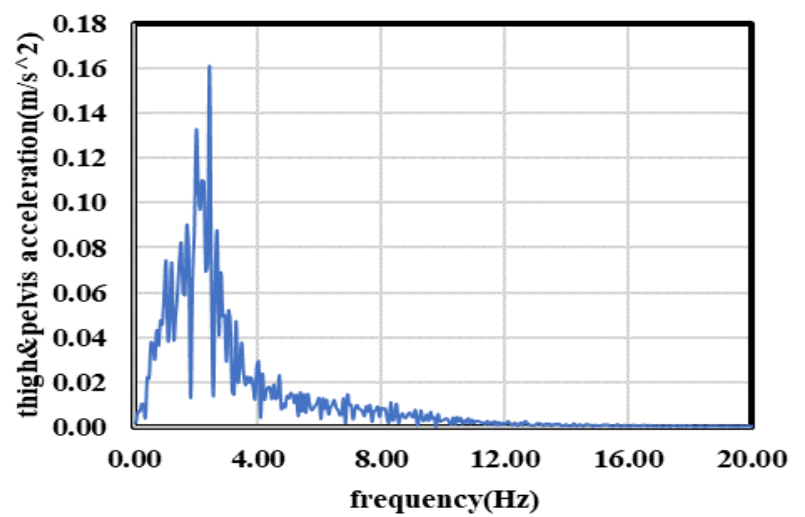

(e)Frequency response of thigh\& pelvis acceleration

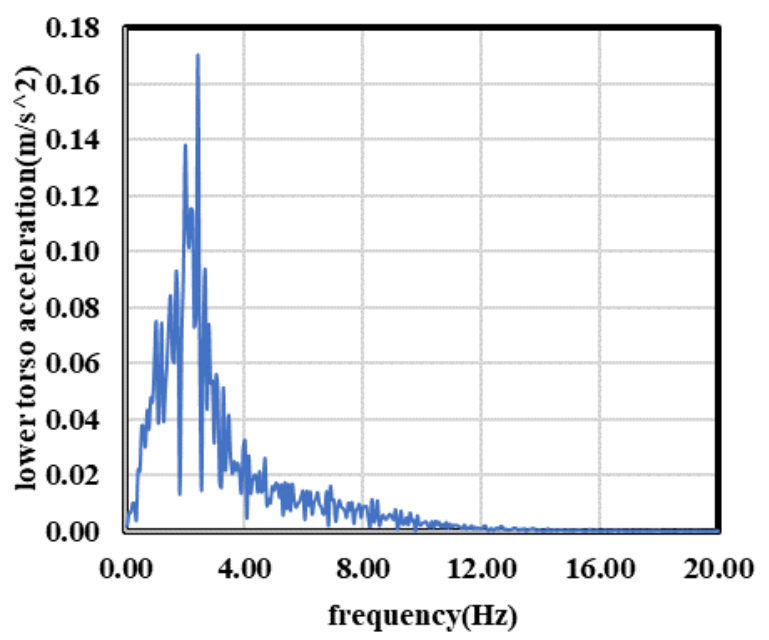

(f)Frequency response of lower torso acceleration

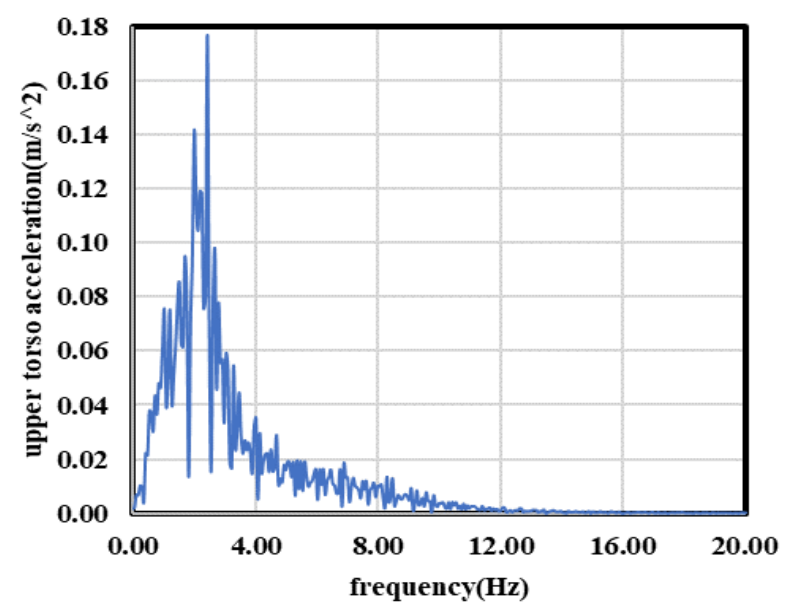

(g)Frequency response of upper torso acceleration

Retrieval Number: 100.1/ijeat.A19181010120

DOI:10.35940/ijeat.A1918.1010120

Journal Website: www.ijeat.org

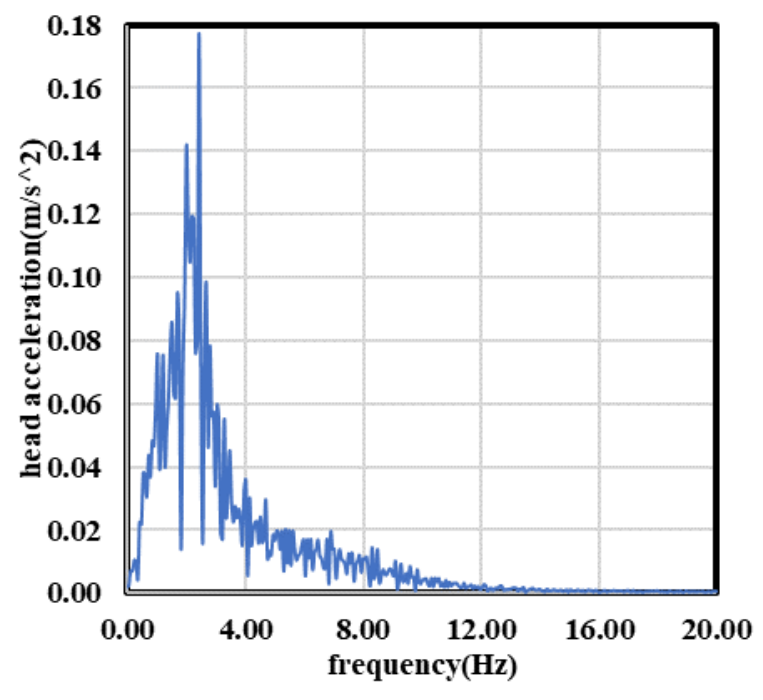

(h)Frequency response of head acceleration

Fig. 5 Frequency domain response of the in-wheel motor quarter EV model

\section{CONCLUSION}

1. The modeling of eight DOF quarter EV model was established and simulated under a MATLAB/Simulink environment. This paper aimed to study the system response in both the time domain and frequency domain.

2. As a result, the seat cushion in the model reduces the vertical acceleration on the passenger organs. The damping coefficient has a significant effect on passenger ride comfort. 3. From these results, it can be concluded that the vehicle the suspension system parameters have a great effect on the design objective. Afterward, the estimation study is performed considering the main design variables. The estimation parameters can reduce both the amplitude and the settling time of unwanted frame motions in the forms of frame acceleration.

\section{REFERENCES}

1. N. Ding, K. Prasad, and T. T. Lie, "The electric vehicle: A review", International Journal of Electric and Hybrid Vehicles, vol. 9, pp. 49, 2017.

2. R. Vos, I. Besselink, and H. Nijmeijer, "Influence of in-wheel motors on the ride comfort of electric vehicles", Proceedings of the 10th International Symposium on Advanced Vehicle Control (AVEC10) pp. 835-840, 2010.

3. M. S. Rahman, and K. M. G. Kibria, "Investigation of Vibration and Ride Characteristics of a Five Degrees of Freedom Vehicle Suspension System", Procedia Engineering, vol. 90, pp. 96-102, 2014.

4. V. Vito, M. Januar, and P. Sejati, "Modeling of Passenger Ride-Comfort Enhancement through Designing Seat Cushion with Scilab-Xcos", Cylinder: Jurnal Ilmiah Teknik Mesin, vol. 4, no. 1, 2018.

5. S. A. A. Bakar, R. Masuda, H. Hashimoto, T. Inaba, H. Jamaluddin, R. A. Rahman, and P. M. Samin, "Improving Electric Vehicle Conversion's Ride and Handling Performance Using Active Suspension System", Advanced Methods, Techniques, and Applications in Modeling and Simulation, pp. 258-267, 2012.

6. A. Seifi, R. Hassannejad, and M. A. Hamed, "Optimum design for passive suspension system of a vehicle to prevent rollover and improve ride comfort under random road excitations", Proceedings of the Institution of Mechanical Engineers, Part K: Journal of Multi-body Dynamics, vol. 230, no. 4, pp. 426-441, 2015.

Published By:

Blue Eyes Intelligence Engineering and Sciences Publication

(C) Copvriaht: All riahts reserved.

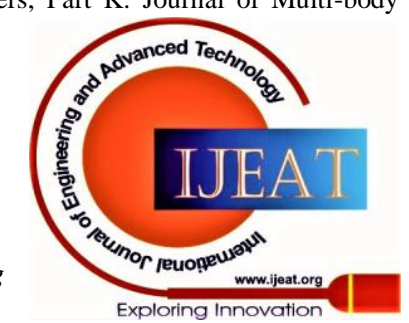


7. H. Fuse, T. Kawabe, and M. Kawamoto, "Speed Control Method of Electric Vehicle for Improving Passenger Ride Quality", Intelligent Control and Automation, vol. 8, no. 1, pp. 29-43, 2016.

8. S. Rajendiran, and P. Lakshmi, "Simulation of PID and fuzzy logic controller for integrated seat suspension of a quarter car with driver model for different road profiles", Journal of Mechanical Science and Technology, vol. 30, no. 10, pp. 4565-4570, 2016.

9. M. Agostinacchio, D. Ciampa, and S. Olita, "The vibrations induced by surface irregularities in road pavements - a Matlab® approach", European Transport Research Review, vol. 6, no. 3, pp. 267-275, 2014.

\section{AUTHORS PROFILE}

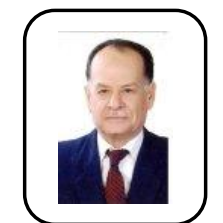

Shawki Abouel-seoud Professor of Automotive Engineering, Helwan University. Verified email at m-eng.helwan.edu.eg. He is specialized in the vehicle dynamics and design.

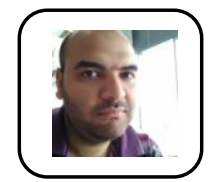

Mohamed N. Mansy Lecturer at the automotive and tractors department, Faculty of Engineering, Mattaria, Helwan university. His PhD thesis concerns the vehicle Noise, vibration, and harshness (NVH) and their effect on the ride comfort.



Manar Eltantawie was born in Mansoura 1966, receive Bachelor degree in 1988, Mansoura University, the Master degree in 1995, and the $\mathrm{PhD}$ degree in Automatic Control, Egypt, in 2005. She has been an professor in Mechanical Engineering Department. Her research interests including control of Magnetic Bearing, MR damper, control of suspension systems, Neuro-Fuzzy, and Fuzzy control

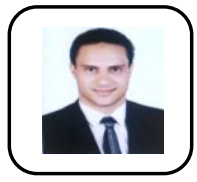

Mahmoud Elshaabany PhD student and lecturer assistant at the automotive and tractors department, Faculty of Engineering, Mattaria, Helwan university. His $\mathrm{PhD}$ thesis concerns the electric vehicle energy storage system and the ride comfort of electric vehicles.

Eid Ouda Lecturer at the automotive and tractors department, Faculty of Engineering, Mattaria, Helwan university. His $\mathrm{PhD}$ thesis concerns the vehicle dynamics.

Published By:

Blue Eyes Intelligence Engineering and Sciences Publication

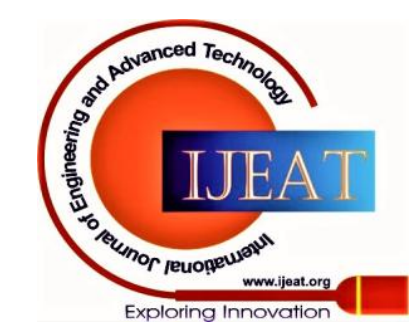

